\title{
Dampak Kuliah Sambil Bekerja Terhadap Indeks Prestasi Mahasiswa Perguruan Tinggi Negeri Dan Swasta di Kabupaten Jember Tahun 2017
}

\author{
Suwarso \\ Akademi Akuntansi IKIP PGRI Jember
}

\begin{abstract}
Abstrack
This study aims to determine the Impact of Lectures While Working Against Achievement Index of State and Private University Students in Jember District in 2017. This research is qualitative by presenting the intreview results in the field. Samples taken are 20 students of State and Private Universities in Jember. The results of this study, the average student who runs college while working is the increase in student achievement index. This means that the impact of students who lectured while working quite positive role in getting the Achievement Index during the lecture process took place. In addition to the increase in Achievement Index, other impacts arise include independence and experience.
\end{abstract}

Keywords: Achievement Index, Student, Work.

\section{LATAR BELAKANG}

Kabupaten Jember adalah kabupaten yang cukup banyak mempunyai perguruan tinggi baik negeri maupun swasta. Salah satu perguruan tinggi negeri di Kabupaten Jember adalah Universitas Jember, sedangkan perguruan tinggi swasta antara lain; Akademi Akuntansi PGRI Jember, Sekolah Tinggi Ilmu Ekonomi Mandala Jember, IKIP PGRI Jember, Universitas Muhammadiyah Jember, dan lain sebagianya.

Corresponding Author:

Email : 5uw2r50@gmail.com

Handphone +62 83847077862 
Dari sekian banyak mahasiswa yang terpencar di beberapa perguruan tinggi di Kabupaten Jember, tidak semua mahasiswa murni hanya kuliah saja, melainkan banyak mahasiswa yang melakukan kegiatanya dengan kuliah sambil bekerja. Mahasiswa yang kuliah sambil bekerja tentunya harus pintar dalam membagi waktu antara pekerjaan dengan waktu kuliah. Banyak alasan mengapa mahasiswa- mahasiswa ini bekerja sambil kuliah, beberapa alasan diantaranya karena kemampuan ekonomi yang terbatas, adanya waktu luang di sela sela perkuliahan, mencari pengalaman, sampai keinginan mencocokan dunia pendidikan dan dunia kerja yang sebenarnya.

Menurut Jacinta dalam artikelnya (2002). Yang mendasari seorang mahasiswa untuk bekerja diantaranya adalah: a.Kebutuhan Finansial : Kebutuhan finansial berupa kebutuhan yang berhubungan dengan faktor ekonomi. Berupa upah, gaji dan penghasilan yang di dapat dari bekerja. b. Kebutuhan Sosial Relasional: Kebutuhan sosial-relasional berupa kebutuhan untukbergaul dengan banyak orang, dapat bertukar pikiran. c. Kebutuhan Aktualisasi Diri Abraham Maslow mengembangkan teori hirarki kebutuhan yang salah satunya mengungkapkan bahwa manusia membutuhkan kebutuhan akan aktualisasi diri,menemukan makna hidupnya melalui aktivitas yang dijalani.

Kuliah sambil bekerja tentunya tidaklah mudah bagi mahasiswa untuk bisa fokus pada perkuliahannya, sehingga sedikit banyak mempengaruhi hasil belajar mahasiswa. Resiko mahasiswa kuliah sambil bekerja, mereka juga harus fokus pada sebuah pekerjaan yang menjadi sambilannya. Mahasiswa terkadang harus rela meninggalkan kuliah dalam beberapa tatap muka karena perusahaan mewajibkan pegawainya untuk tukar shif masuk kerja atau untuk bekerja lebih dari biasanya (lembur). Disini bisa di lihat bahwa ketika mahasiswa yang bekerja di wajibkan oleh perusahaan tukar shif masuk kerja dan melakukan lembur di pastikan sudah tidak bisa masuk kuliah. Pada saat mahasiswa tersebut misalkan mendadak di wajibkan lembur oleh perusahan, tentunya sudah banyak materi perkuliahan dalam suatu mata kuliah tersebut ketinggalan.

Dari latar belakang diatas penulis menemukan beberapa permasalahan mahasiswa kuliah sambil bekerja, sehingga menarik untuk diteliti lebih dalam 
mengenai dampak kuliah sambil bekerja terhadap indeks prestasi mahasiswa perguruan tinggi negeri dan swasta di kabupaten Jember.

Dari uraian latar belakang diatas, maka pokok permasalahan dapat dirumuskan sebagai berikut : Dampak Kuliah Sambil Bekerja Terhadap Indeks Prestasi Mahasiswa Perguruan Tinggi Negeri Dan Swasta Di Kabupaten Jember.

Berdasarkan rumusan masalah, maka tujuan penelitian ini adalah ingin mengetahui Dampak Kuliah Sambil Bekerja Terhadap Indeks Prestasi Mahasiswa Perguruan Tinggi Negeri Dan Swasta Di Kabupaten Jember.

\section{TINJAUAN PUSTAKA}

\section{dampak}

Dampak secara sederhana bisa diartikan sebagai pengaruh atau akibat. Dalam setiap keputusan yang diambil oleh seorang atasan biasanya mempunyai dampak tersendiri, baik itu dampak positif maupun dampak negatif. Dampak juga bisa merupakan proses lanjutan dari sebuah pelaksanaan pengawasan internal. Seorang pemimpin yang handal sudah selayaknya bisa memprediksi jenis dampak yang akan terjadi atas sebuah keputusan yang akan diambil.

Pengertian dampak menurut Kamus Besar Bahasa Indonesia adalah pengaruh kuat yang mendatangkan akibat, baik negatif maupun positif. Sedangkan Pengertian dampak menurut para ahli adalah sebagai berikut :

\section{OTTO SOEMARWOTO}

Dampak adalah pengaruh suatu kegiatan

\section{HIRO TUGIMAN}

Dampak adalah sesuatu yang bersifat objektif

\section{ARESANDI S}

Dampak adalah besarnya nilai yang kita tambahkan pada hidup atau dunia seseorang

\section{C. JOTIN KHISTY \& B. KENT LALL}

Dampak merupakan pengaruh - pengaruh yang dimiliki pelayanan angkutan umum terhadap lingkungan sekitar dan keseluruhan kawasan yang dilayaninya

5. SCHEMEL (1976) 
Dampak adalah tingkat perusakan terhadap tata-guna tanak lainnya yang ditimbulkan oleh suatu pemanfaatan lingkungan tertentu

\section{HARI SABARI}

Dampak adalah sesuatu yang muncul setelah adanya suatu kejadian. ( http://carapedia.com/pengertian_definisi_dampak_info2123.html)

Dari beberapa pengertian diatas dapat ditarik kesimpulan bahwa pengertian dampak adalah akibat yang ditimbulkan dari suatu sebab yang menghasilkan akibat positif maupun negatif.

\section{a. Mahasiswa}

Menurut Salim P dan Salim Y (2002) dalam bukunya menyebutkan mahasiswa sebagai orang yang terdaftar dan menjalani pendidikan dalam perguruan tinggi. Selain itu Badudu dan Zaih (2001) juga memaparkan mahasiswa sebagai siswa perguruan tinggi.

Dari dua pendapat ahli diatas bisa disimpulkan bahawa mahasiswa adalah seseorang yang sedang belajar pada sebuah perguruan tinggi baik swasta maupun negeri.

\section{b. Pekerja}

Menurut suherman rosyidi (2005:56) didalam ilmu ekonomi, yang dimaksud istilah tenaga kerja manusia (atau labor) bukanlah semta-mata kekuatan manusia untuk mencangkul, menggergaji, bertukang, dan segala kegiatan fisik lainnya. Hal ini dimaksudkan disini memang bukanlah sekedar labor atau tenaga kerja saja, tetapi lebih luas lagi, yaitu human resources (sumber daya manusia)

\section{c. Indeks Prestasi}

Pada tingkat pendidikan tinggi, IP dihitung sebagai rerata norma nilai yang diperoleh seorang mahasiswa pada mata kuliah tersebut setelah diberi bobot dengan "Angka Kredit". Norma nilai berkisar antara 4 (A, terbaik) sampai 0 (E, gagal). Angka Kredit ditentukan besarnya (biasanya 1 sampai 4 Satuan Kredit

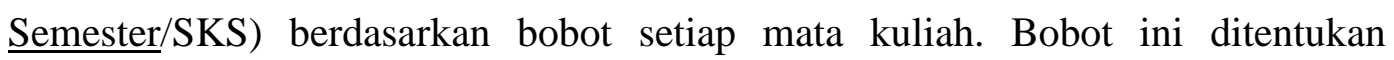
berdasarkan pentingnya mata kuliah tersebut dalam membentuk kompetensi lulusan. IP dihitung untuk setiap semester.Indeks Prestasi Kumulatif adalah penghitungan IP dengan menggabungkan semua mata kuliah yang telah ditempuh 
sampai suatu semester tertentu. Indeks Prestasi Semester adalah penghitungan IP dengan semua mata kuliah yang telah ditempuh untuk tiap semester tertentu. (https://id.wikipedia.org/wiki/Indeks_prestasi).

\section{Penelitian Terdahulu}

Menurut Yunus Radianto Wensly. S dalam penelitiannya tahun 2016 yang berjudul "DAMPAK KULIAH SAMBIL BEKERJA (Studi Kasus Mahasiswa Universitas Riau yang Bekerja sebagai Operator Warnet), Penelitan ini menggunakan metode pendekatan deskriptif kualitatif dengan fenomenologi. Sumber data dalam penelitian ini berupa manusia (responden), aktivitas dan tempat, serta dokumen lain yang menunjang penelitian ini. Teknik cuplikan yang digunakan dalam penelitian ini adalah purposive. Pengumpulan data menggunakan observasi langsung, wawancara dan dokumentasi. Untuk mencari validitas data menggunakan trianggulasi sumber (data). Teknik analisis dengan menggunakan model analisis interaktif. Hasil dari penelitian menunujkkan bahwa Dampak positif dari bekerja sambil kuliah yaitu, mendapatkan pengetahuan dan pengalaman baru, dapat hidup mandiri serta dapat menambah teman atau perluasan pergaulan. Sedangkan dampak negatif timbul ketika mahasiswa tidak dapat membagi waktu dengan baik. Dampak negatif tersebut yaitu datang terlambat dalam perkuliahan, terlambat dalam mengumpulkan tugas, berkurangnya waktu untuk belajar, berkurangnya minat untuk kuliah, serta kurangnya interaksi dengan teman satu kelas.

Achmad hipjillah dan Nurul Badriyah . 2015. Dalam penelitianya yang berjudul " Mahasiswa bekerja paruh waktu: antara konsusmsi dan prestasi akademik ( Study pada mahasiswa bekerja paruh waktudi Uno Board Game Cafe). Metode penelitian ini menggunakan penelitian kualitataif, sumber data primer dan skunder. Hasil penelitian tidak adanya keterkaitan antara tingkat konsusmsi dengan prestasi akademik mahasiswa bekerja paruh waktu, melainkan ada keterkaitan antara satu faktor dengan faktor lain , seperti tingkat konsumsi terkait dengan upah/gaji dan tingkat prestasi akademik terkait dengan manajemen waktu, dukungan perusahaan serta motivasi prestasi. 
Pujiyanto .2005. "Pengaruh "Bekerja" Terhadap Prestasi Mahasiswa Program Study Desain Komunikasi Visual Jurusan Seni Dan Desain Fakultas Satra UM". Model rancangan penelitian deskriptif kualitatif dan kuantitaif, tekhnik pengumpulan data dengan menggunakan instrumen kuisioner terbuka. Hasil penelilitian poin ketiga adalah perkembangan study bagi mahasiswa program studi desain komunikasi visual selama 3 semester rata-rata tampak mengalami kenaikan jumlah sks. Kenaikan jumlah sks ini kurang di manfaatkan bagi mahasiswa yang mengutamakan pekerjaan diluar untuk meningkatkan prestasinya, hal ini terbukti adanya penurunan IP tiap semester, sebaliknya bagi mahasiswa yang dapat memanfaatkan waktunya akan mendapatakan hasil IP tinggi atau memiliki prestasi di atas rata-rata kelas.

\section{METODE PENELITIAN}

\section{a. Populasi dan Sampel}

Menurut Singgih Santoso (2002:49) populasi adalah sekumpulan orang atau objek yang memiliki kesamaan dalam satu atau beberapa hal dan yang membentuk masalah pokok dalam satu riset tertentu. Populasi merupakan kelompok subyek yang hendak dikenai.

\section{b. Jenis data, Sumber data dan Tekhni pengumpulan data}

Penelitian ini bersifat kualitatif dengan mengemukakan hasil intreview di lapangan, data diperoleh dari beberapa mahasiswa perguruan tinggi negeri maupun swasta yang ada di Kabupaten Jember. Mahasiswa sebagai obyek penelitian. Sumber data yang digunakan yaitu data skunder, sedangkan pengumpulan data menggunakan metode wawancara dan studi pustaka.

Tabel 1.1 Daftar mahasiswa Perguruan tinggi Negeri dan Swasta di Kabupaten Jember yang bekerja.

\begin{tabular}{|r|l|l|l|}
\hline \multicolumn{1}{|l|}{ No } & Nama & Perguruan Tinggi & Perusahaan \\
\hline 1. & Sendi Fitriani & Akademi Akuntansi PGRI Jember & PT. BMI \\
\hline 2. & Jamalul lail & Akademi Akuntansi PGRI Jember & PT. Media Plus \\
\hline 3. & Fitri Ana Ariska & Akademi Akuntansi PGRI Jember & PT. FAST \\
\hline 4. & Taufik Hidayat & Politeknik Jember & Dejavu cafe \\
\hline
\end{tabular}




\begin{tabular}{|r|l|l|l|}
\hline 5. & Muzayana & Universitas Jember & Dejavu Cafe \\
\hline 6. & Ahmad Yulianto & Universitas Muhamadiyah Jember & Dejavu Cafe \\
\hline 7. & Veri yoga & Politeknik Jember & Koperasi \\
\hline 8. & Budiono & IKIP PGRI Jember & Smart Cafe \\
\hline 9. & Agus Junaidi & IKIP PGRI Jember & Smart Cafe \\
\hline 10. & Desi Emita Putri & Universitas Muhamadiyah Jember & Smart cafe \\
\hline 11. & Rudi hartono & Universtas Islam Jember & Smart cafe \\
\hline 12. & Andi Wandiro & STIE mandala Jember & Smart cafe \\
\hline 13. & Satya luhur Wicaksono & Universitas Jember & EO (OK Production) \\
\hline 14. & Muhammad Bagus A & Universitas Islam jember & Papuma Resto \\
\hline 15. & Siska Ambarwati & Universitas Mohamad Sroeji Jember & PT.Luna Tour Travel \\
\hline 16. & Kusnia Indriyani & Universitas Mohamad Sroeji Jember & Toko Komputer \\
\hline 17. & Mar,atus Sholeha & Universitas Jember & Can Teen Cafe \\
\hline 18. & Devi Wulandari & Universitas Jember & Can Teen Cafe \\
\hline 19. & Dila & Universitas Jember & Can Teen Cafe \\
\hline 20. & Yanuar Rizki & STIE Mandala Jember & Can Teen Cafe \\
\hline
\end{tabular}

Data Diolah : Tahun 2017

\section{c. Metode Analisis Data}

Menurut Moleong (2011:149), Analisis data kualitatif adalah upaya yang dilakukan dengan jalan bekerja dengan data, mengorganisasikan data, memilahmilahnya menjadi satuan yang datapat dikelolah, mensintesiskan, mencari dan menemukan pola, menemukan apa yang penting dan apa yang dipelajari dan memutuskan apa yang dapat diceritakan kepada orang lain.

Menurut Burhan Bungin (2011:149) mengatakan bahwa analisis data kualitatif prosesnya sebagai berikut:

1. proses mencatat yang menghasilakan catatan lapangan, dengan hal itu diberi kode agar sumber datanya tetap dapat ditelusuri.

2. Mengumpulkan, memilah-milah, mengklasifikasikan, menyintesiskan, membuat ikhtisar dan membuat indeksnya. 
3. Berfikir, dengan jalan membuat agar kategori data itu mempunyai makna, mencari dan menemukan pola dan hubungan-hubungan.

4. Membuat temuan-temuan umum.

\section{PEMBAHASAN}

Hasil dari beberapa wawancara yang dihasilkan pada saat dilapangan dapat dijabarkan sebagai berikut :

Dalam melakukan observasi penulis mengelompokkan responden yaitu mahasiswa perguruan tinggi negeri dan perguruan tinggi swasta. Terdapat perbedaan mendasar diantara keduanya, perbedaan tersebut seperti yang dijelaskan dibawah ini.

“ Muzayana, Universitas Jember Fakultas Ilmu Pendidikan” mengatakan, bahwa kuliah sambil bekerja ini tidak pernah terbayangkan, selama melaksanakan perkuliahan yang biayanya ternyata diluar perkiraan khususnya biaya hidup yang sangat tinggi, sehingga mengharuskan saya berupaya untuk bisa bertahan agar tetap bisa melajutkan perkuliahan. Karena saya berasal dari kota nganjuk dan ekonomi orang tua saya bisa dibilang dibawah rata-rata, membuat saya sadar untuk mencari tambahan atau pekerjaan guna menyambung biaya hidup dan perkuliahan selama di Universutas Jember. Selama saya bekerja sambil kuliah Indeks Prestasi (IP) yang saya dapat bisa dikatakan lumayan bagus, karena IP saya selalu diatas 3,0. Hambatan selama ini kuliah sambil bekerja adalah rasa ngantuk yang tidak bisa di tahan ketika masuk kuliah pagi, karena saya bekerja di sore sampai malam hari. Dampak yang paling terasa ketika saya menempuh mata kuliah skripsi, terlambatnya atau molor dalam penyusunan dikarenakan adanya split ditempat kerja saya, kadang masuk pagi dan kadang sore hari sehingga kesempatan dalam bertemu dosen pembimbing kres dengan pekerjaan di pagi hari. Akan tetapi saya bangga karena bisa membantu orang tua.

“ Desi Emita Putri, Universitas Muhammadiyah Jember, jurusan Informatika ", mengemukakan, pada awal perkuliahan masalah perekonomian keluarga awalnya baik-baik saja, namun ketika ayah meninggal, ibu yang mebiayai kuliah. Meski ibu saya mampu untuk membiayai kuliah saya, saya 
sebagai anak pertama merasa tergugah untuk mencari tambahan biaya, minimal biaya hidup selama kuliah, dan saya memutuskan untuk mencari pekerjaan pada semester 6. Saat itu saya melamar kerja di Smart Cafe yaitu sebagai kasir, tentunya saya dalam bekerja sambil kuliah harus bisa membagi waktu antara kerja dan kuliah. Satu bulan pertama bekerja memang sangat sulit mempraktikkan waktu yang sudah saya buat agar keduanya bisa berjalan dengan baik, ketika ujian akhir semester khususnya saya benar-benar ekstra membagi waktu. Posisi kasir di tempat kerja saya, bisa di bilang lumayan berat karena, saya harus mengitung stok barang untuk mecocokkan keuangan selama transaksi. Saat pertama kerja Indeks Prestasi (IP) yang saya dapat turun, meski saya sudah maksimal dalam pembagian waktu, karena saya merasa beban pikiran yang saya rasakan double, ini diakibatkan fisik dan fikiran saya belum benar-benar mampu bekerja secara bersamaan. Dalam semester selanjutnya, Alhamduliah IP saya sudah mulai menunjukkan kenakan yang signifikan, bahkan selalu naik tiap semesternya.

“Agus Junaidi, IKIP PGRI Jember, jurusan Sejarah”, menyampaikan seiring berjalannya perkuliahan, saya merasakan banyak sekali waktu yang longgar, sehingga waktu yang longgar ini tidak banyak kegiatan yang dilakukan. Sampai suatu hari saya iseng melamar pekerjaan, dan ternyata saya diterima kerja. Kerja sambil kuliah menurut saya adalah proses saya melatih mental untuk berinteraksi dengan dunia kerja yang sesusungguhnya, dan saya juga ingin tau bagiamana sulitya bekerja sambil kuliah seperti yang dirasakan oleh beberapa teman saya yang bekerja sambil kuliah. Ternyata setelah saya melakukan dan merasakan sendiri kerja sambil kuliah Indeks Prestasi (IP) yang saya dapat setelah bekerja sambil kuliah, mendapatkan IP yang lumayan naik. Ini mungkin karena saya merasakan betapa sulitnya mencari uang. Sehingga saya berfikir, bagaimana saya harus kuliah dengan tepat waktu dan mendapatkan IP yang bagus, agar cepat lulus dan tidak menghabiskan biaya yang membengkak karena kuliah yang molor.

“Mar'atus Naini Soleha, Akademi Akuntansi PGRI Jember, jurusan Akuntansi megatakan", selama saya bekerja sambil kuliah, Indeks Prestasi (IP) saya naik, meski naiknya tidak terlalu tinggi, Karena ketika saya bekerja, bidang yang saya tekuni sesuai dengan jurusan yang saya ambil diperkuliahan yaitu 
dibagian penghitungan persediaan bahan baku. Kenapa IP saya bisa meningkat, menurut saya karena ilmu yang saya peroleh di bangku perkuliahan dapat saya terapkan di dunia kerja, dan sebaliknya terkadang ilmu yang saya dapat di tempat kerja saya, banyak mendukung saya dalam hal mempelajari ilmu-ilmu akuntansi yang ketika dikelas kurang memahami materi.

"Veri Yoga, Politeknik Jember Jurusan Manajemen industri", mengatakan sebagai seorang laki-laki setelah lulus SMA dan melanjutkan perkuliahan, wajib untuk membiayai hidupnya sendiri. Karena saya ketika lulus SMA dan memutuskan kuliah dengan biaya sendiri dengan cara kerja, untuk biaya hidup dan kuliah. Ternyata niat baik yang ada dibenak saya di lancarkan oleh Tuhan Yang Maha Esa, karena saya bisa kuliah sampai lulus dengan biaya sendiri. Tentunya dalam menjalankan kuliah dengan kerja bukan hal yang sangat gampang dan juga tidak sulit. Tergantung kita bisa membagi waktu antara kerja dan kuliah, tetapi hal yang saya rasakan ketika kerja sambil kuliah, kerja yang selalu saya utamakan, karena kalau saya tidak mengutamakan kerja, saya tidak bisa membiayai hidup dan kuliah saya. Ibaratnya seperti dua belah mata pisau, harus ada yang diutamakan. Pengalaman saya bekerja sambil kuliah itu pasti ada resikonya, dalam perkuliahan saya melihat hasilnya melalui Indeks Prestasi (IP) yang saya peroleh tiap semester. Saya bersyukur meski saya mengutamakan pekerjaaan IP yang saya dapatkan tergolong lumayan bagus, tetapi selalu stagnan naik dan turunnya hanya dalam enol koma $(0$,

Rudi Hartono, Universitas Islam Jember jurusan Ilmu Admiistrasi”, mengemukakan jika saya fokus diperkulihan naik tetapi kalau mengutamakan kerja turun. Awal saya bekerja, saya masih beradaptasi dengan pekerjaan saya sehingga semester pertama saat bekerja Indeks Prestasi (IP) saya turun. Pada semester selanjutnya saya sudah mampu beradaptasi antara perkuliahan dan kerja, saya leboh gampang mengatur keduanya secara seimbang. Banyak pengalaman yang saya dapatkan pada saat kuliah sambil bekerja, yang pengalaman itu tidak saya dapatkan di bangku perkuliahan, seperti halnya dalam hal membagi waktu antara belajar, kuliah dan bekerja. 
"Yanuar Rizki STIE MANDALA jurusan Ekonomi Pembangunan" menyampaikan,bahwa pada saat kuliah sambil bekrja Indeks Prestasi (IP) mengalami kenaikan meskipun tidak signnifikan. Saya kuliah dengan biaya sendiri, biaya pendidikan gratis tiap semester, tetapi dikenakanbiaya KKN, KKL, wisuda. Penghasilan selama bekerja saya kumpulkan untuk biaya tersebut. Pada saat kuliah sambil kerja saya banyak belajar dalam hal membagi waktu, terkadang saya menyempatkan belajar ditempat kerja. Saya sangat beryukur bisa kuliah sambil bekerja karena saya banyak belajar mamanage waktu, dan belajar mempertahankan prestasi belajar saya.

Dari hasil selama saya melakukan wawancara, banyak faktor yang mengharuskan mahasiswa mahasiswi tersebut untuk menjalankan proses perkuliahannya dengan disambi bekerja. Beberapa faktor mahasiswa mahasiswi tersebut kuliah sambil bekerja antara lain :

1. Faktor yang paling utama adalah karena kendala biaya, baik biaya pendidikan kuliah maupun biaya hidup selama kuliah.

2. Faktor Force Majeur, dimana mahasiswa tidak pernah menduga masalah perekonomian/ masalah keluaraga yang diadapi oleh keluarganya, seperti kematian, perceraian orang tua dan pemutusan hubungan kerja orang tua mahasiswa.

3. faktor kemandirian mahasiswa dimana mahasiswa ingin mengetahui seberapa besar mahasiswa tersebut dapat bertanggung jawab terhadap dirinya sendiri.

4. faktor waktu, yaitu luangnya waktu yang dimiliki oleh mahasiswa tersebut, sehingga mereka mencari kesibukan dengan bekerja.

5. Faktor Pengalaman, mahasiswa mencoba mencari pengetahuan, diluar pengetahuan akadamik.

6. Faktor Perbandingan, mahasiswa juga ingin mempraktekkan atau membandingkan antara ilmu yang diperoleh selama kuliah dengan dunia kerja sesungguhnya. 
Hasil penelitian Bahwa Dampak Kuliah Sambil Bekerja Terhadap Indeks Prestasi Mahasiswa Perguruan Tinggi Negeri Dan Swasta Di Kabupaten Jember adalah Mahasiswa rata-rata mengalami kenaikan Indeks Prestasi (IP) pada saat bekerja. Secara empiris temuan hasil penelitian ini mendukung hasil penelitian Yunus Radianto Wensly. S tahun 2016 dan Pujiyanto tahun 2005.

Selain itu dampak lain yang di akibatkan mahasiswa sambil bekerja antara lain :

1. Mahasiswa yang semula tidak disiplin maasalah waktu menjadi mampu memanage waktu antara perkuilahan dan pekerjaannya secara tepat dan seimbang.

2. Pribadi yang mempunyai rasa tanggung jawab, minimal mampu bertanggung jawab pada diri sendiri .

3. Mental yang kuat, dimana mahasiswa harus menghilangkan rasa egois, malu dan semangat untuk memperbaiki diri baik dalam hal prestasi akademik maupun non akademik.

4. Pengalaman dan pengetahuan mahasiswa tidak hanya didadapat pada bangku perkuliahan.

\section{KESIMPULAN}

Berdasarkan hasil penelitian, Kesimpulan yang bisa diambil, ternyata dampak kuliah sambil bekerja terhadap Indeks Prestasi Mahasiswa, rata-rata mahasiswa yang menjalankan kuliah sambil bekerja adalah meningkatnya Indeks Prestasi mahasiswa. Artinya dampak yang ditimbulkan mahasiswa yang kuliah sambil bekerja cukup positip perannya dalam mendapat Indeks Prestasi selama proses perkuliahan berlangsung.

Selain meningkatnya Indeks Prestasi, dampak lain yang timbul antara lain kemandirian mahasiswa pada saat mahasiswa harus mampu melanjutkan perkuliahan pada saat mahasiswa mengalami kendala biaya, baik biaya pendidikan perkuliahan maupun biaya hidup selama kuliah. Disamping itu segi positif lainnya, mahasiswa yang kuliah sambil bekerja banyak mendapatkan pengetahauan dan pengalaman yang tidak diperoleh mahasiswa di bangku 
perkuliahan, sehingga mahasiswa siap untuk memasuki dunia kerja yang sesungguhnya.

\section{DAFTAR PUSTAKA}

Achmad hipjillah . 2015. " Mahasiswa bekerja paruh waktu: antara konsusmsi dan prestasi akademik ( Study pada mahasiswa bekerja paruh waktudi Uno Board Game Cafe)" Fakultas Ekonomi dan Bisni. Universitas Brawijaya Malang.

Badudu, J. S. \& Zaih, S. M. (2001). Kamus umum Bahasa Indonesia. Jakarta : Pustaka Sinar Harapan

http://carapedia.com/pengertian_definisi_dampak_info2123.html/ [ 12 Januari 2017]

https://id.wikipedia.org/wiki/Indeks_prestasi [09 Mei 2017]

H. M. Burhan Bungin, 2011. Penelitian Kualitatif, Jakarta: Prenada Media Group Jacinta, R. F. (2002). Wanita Bekerja. WEB: Kompas Cyber Media

Lexy J. Moleong, 1999. Metodologi Penelitian Kualitatif, Bandung: PT. Remaja Rosdakarya

Pujiyanto dan Nurul Badriyah. 2005. "Pengaruh "Bekerja" Terhadap Prestasi Mahasiswa Program Study Desain Komunikasi Visual Jurusan Seni Dan Desain Fakultas Satra UM”. Jurusan Seni dan Desain Fakultas Sastra. Universitas Negeri Malang.

Rosyidi, Suherman (2005). Pengantar Teori Ekonomi. Jakarta. PT. Raja Grafindo Persada.

Santoso, Singgih. 2002. Buku Latihan SPSS Statistik Parametik. PT. Elex Media Komputindo Gramedia : Jakarta

Salim, P. \& Salim, Y. (2002).Kamus Bahasa Indonesia kontemporer.Jakarta : Modern English Press.

Yunus Radianto Wensly. S . 2016.” DAMPAK KULIAH SAMBIL BEKERJA (Studi Kasus Mahasiswa Universitas Riau yang Bekerja sebagai Operator Warnet)" http://www.e-jurnal.com/2017/02/dampak-kuliah-sambil-bekerjastudi.html. 